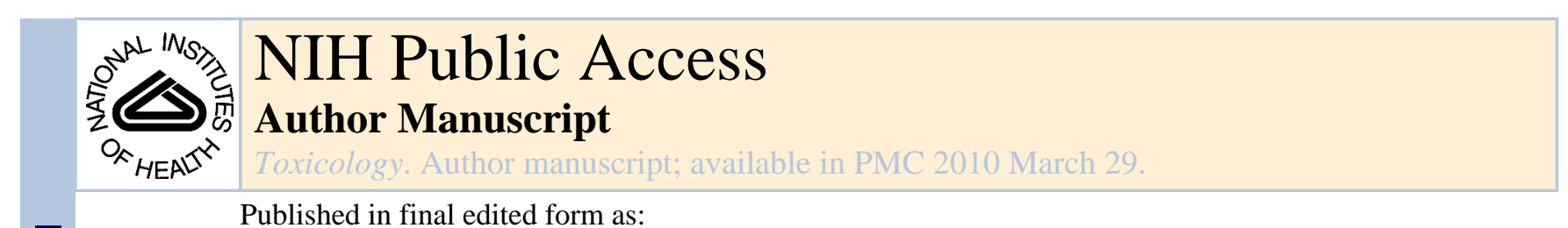

Published in final edited form as:

Toxicology. 2009 March 29; 257(3): 173. doi:10.1016/j.tox.2008.12.015.

\title{
Reply to the letter to the editor by Bretholz et al
}

\author{
Steven B. Bird, MD FACEP* \\ University of Massachusetts Medical School
}

I'd like to thank the NYC Poison Center for their letter regarding the manuscript "OpdA, a bacterial organophosphorus hydrolase, prevents lethality in rats after poisoning with highly toxic organophosphorus pesticides." A close review of the manuscript serves to effectively answer their first misinterpretation of the paper. Hoffman et al are mistaken when writing that the OPs were administered simultaneously with the OP hydrolase. As stated in the manuscript and Fig $3 \mathrm{~b}$, in the parathion model OpdA was given 10 minutes after the parathion.

The authors are correct in stating that in the developed world, standard therapy for OP poisoning includes atropine along with an oxime. Atropine or other anti-muscarinic drug was not included in any treatment group for two reasons. Firstly, it is thought that high circulating OP concentrations re-inhibit any acetylcholinesterase that has been reactivated by 2-PAM. It therefore follows that if plasma concentrations of an OP could be decreased, the acetylcholinesterase could be regenerated and not undergo re-inhibition. The study therefore sought to determine if use of an OP hydrolase could increase the efficacy of 2-PAM (without atropine) by such a mechanism. While the lack of serum OP concentrations in the study limits the full interpretation of the data, the results are consistent with the hypothesis. Secondly, if one assumes that adding atropine would increase survival at 4 or 24 hours to $80 \%$ (not an unreasonable assumption in an animal model not involving mechanical ventilation), then more than 30 animals would be required in each experimental group in order to show statistical significance.

Hoffman et al. are surely correct in their assessment that further study into the area of OP hydrolases for organophosphorus pesticide poisoning is clearly warranted.

*e-mail: Steven.Bird@umassmemorial.org.

Publisher's Disclaimer: This is a PDF file of an unedited manuscript that has been accepted for publication. As a service to our customers we are providing this early version of the manuscript. The manuscript will undergo copyediting, typesetting, and review of the resulting proof before it is published in its final citable form. Please note that during the production process errors may be discovered which could affect the content, and all legal disclaimers that apply to the journal pertain. 